\title{
Juventudes coloridas: \\ sociabilidade, consumo e subjetividade entre jovens LGBT em João Pessoa
}

Mónica Franch ${ }^{1}$

Resumo: Este artigo busca refletir sobre as dinâmicas de sociabilidade juvenil do segmento conhecido como 'LGBT' no município de João Pessoa (Paraíba). A partir da descrição contrastiva de dois "pedaços" de lazer juvenil da cidade: o Empório Café e o Carboni/On the Rocks, o trabalho discute possibilidades de identificação que se aproximam e afastam das categorias mobilizadas pelos movimentos sociais.

Palavras-chave: juventude LGBT, sociabilidade, subjetividades, consumo.

Abstract: This essay discusses the dynamics of sociability, among young people segment known as 'LGBT' in the city of João Pessoa (Paraíba). From the contrastive description of two "pieces" leisure city youth: the Coffee Emporium and Carboni / On the Rocks, the paper discusses possibilities of identification that approach and depart from the categories mobilized by social movements.

Keywords: LGBT youth, sociability, subjectivities, consumption.

"Quem é colorido vai para o Encontro da Juventude LGBT!" Foi com estas palavras, postadas na rede social Facebook, que uma aluna da Universidade Federal da Paraíba conclamava outros jovens a participarem de uma das atividades do projeto de extensão "Direitos Humanos e Diversidade Sexual", desenvolvido desde o início de 2012 nos campi de João Pessoa e de Rio Tinto da $\mathrm{UFPB}^{2}$. Como se sabe, a metáfora das cores do arco-íris faz parte de uma estratégia de luta política, que buscou retirar a homossexualidade do campo das patologias, substituindo as representações negativas desse fenômeno por uma celebração da diversidade sexual. Ao escolher o arco-íris como símbolo emblemático do

\footnotetext{
${ }^{1}$ Programa de Pós-Graduação em Antropologia/UFPB.

2 Projeto financiado pelo MEC, através do Edital PROEXT 2011. É coordenado pela Profa. Dra. Silvana Nascimento, e está vinculado ao Núcleo de Cidadania e de Direitos Humanos da UFPB, e aos grupos de pesquisa GUETU - Grupo de Etnografias Urbanas e GRUPESSC Grupo de Pesquisas em Saúde, Sociedade e Cultura.
}

Latitude, vol. 6, n¹, pp.06-21, 2012

DOI: https://doi.org/10.28998/2179-5428.20120106 
Juventudes coloridas: sociabilidade, consumo e subjetividade entre jovens GBT em João Pessoa.

movimento, o mundo straight passaria a ser representado em preto-e-branco, dicotômico, entediante e cinzento, contrastando com as cores vívidas dos alegres gays, das travestis e das dragqueens, entre outras várias maneiras de conjugar desejos, atitudes e identidades ${ }^{3}$.

Surgida nos gloriosos anos 1970, a metáfora da cor continua presente na forma pela qual muitos jovens LGBT se expressam e entendem atualmente no Estado da Paraíba, como mostra a fala da referida estudante. Este trabalho acompanha alguns desses jovens em seus locais de encontro, reais e virtuais, apresentando suas diversas cores, marcadas pelo consumo de bens simbólicos e por performances distintivas. Perfazendo o "mapa moral" de João Pessoa, é possível perceber a potencialidade da cor como metáfora política LGBT, mas também as muitas clivagens que marcam esse coletivo, e que são postas em cena nos bares, boates e redes sociais da capital paraibana.

\section{Introdução: nota metodológica}

Em maio de 2012, o Núcleo de Cidadania e Direitos Humanos da UFPB iniciou um projeto de extensão universitária voltado à população LGBT (lésbicas, gays, bissexuais, travestis, transgêneros e transexuais) do Estado da Paraíba. O projeto objetiva ampliar e fortalecer a cidadania e os direitos humanos dessa população, por meio de ações e cursos de formação social e política, organização de encontros culturais e artísticos, bem como através da elaboração de publicações, materiais didáticos e de divulgação. Busca, igualmente, construir um espaço permanente de diálogo da Universidade Federal da Paraíba com os movimentos sociais LGBT no Estado, além de promover discussões sobre o preconceito homofóbico dentro e fora da instituição.

As atividades que informam este ensaio correspondem, especificamente, a um dos subprojetos desenvolvido no marco desse projeto de extensão, intitulado "Formação política da juventude LGBT". Como seu nome indica, o referido subprojeto centra-se no segmento juvenil dessa população, tendo por objetivo promover sua participação política tanto nas instâncias do movimento social existente, como em seus espaços cotidianos de encontro e sociabilidade - bares, boates, ruas, praças etc. -, principalmente por meio de eventos culturais que

\footnotetext{
${ }^{3}$ Para uma revisão histórica do movimento LGBT no Brasil, recomenda-se a consulta de Simões e Facchini (2009), Facchini (2005).

4 Coordenação: Silvana Nascimento e Mónica Franch. Fotógrafo:Paulo Rossi. Bolsistas: Elton Bruno Amaral de Oliveira, Felipe Bracho, Gaudioso Gomes, Luarna Relva Cortez, Marcela, Susi Any Veloso, Walquíria Nascimento. Voluntários: Thiago Oliveira e Jainara Oliveira.
} 
problematizem questões de cidadania e direitos humanos relativos à juventude LGBT.

Como parte das atividades do projeto, uma equipe de estudantes - também jovens e alguns deles pertencentes ao segmento LGBT - está realizando um mapeamento dos espaços de lazer voltados a esse público em João Pessoa e na cidade de Rio Tinto (Litoral Norte da Paraíba). O mapeamento é necessário para localizar os espaços passíveis de intervenções políticas, e também para conhecer aspectos da dinâmica desse segmento juvenil: suas identidades, identificações e distinções, sua maior ou menor afinidade com a temática LGBT, o modo como se dá, enfim, sua presença nos diversos espaços de lazer juvenil existentes em João Pessoa e em Rio Tinto.

O projeto também incluiu a organização do I Encontro Estadual da Juventude LGBT da Paraíba, que foi realizado no mês de junho na UFPB. A organização do evento colocou em contato jovens universitários e militantes dos diversos movimentos sociais LGBT atuantes em João Pessoa: o MEL - Movimento do Espírito Lilás, o Movimento de Mulheres Lésbicas Maria Quitéria e a Associação das Travestis da Paraíba - ASTRAPA. O encontro levou até a UFPB mais de cem jovens de várias cidades do Estado, para participação em debates, oficinas, rodas de conversa e, não menos importante, em eventos culturais. As falas proferidas nesses dois dias oferecem um contraponto à observação nos espaços de lazer, permitindo assim um acesso ao universo jovem LGBT desde várias posições.

Também faz parte do projeto de extensão a realização de entrevistas com lideranças jovens do movimento no Estado, bem como o desenvolvimento de intervenções de caráter artístico-político em espaços de sociabilidade LGBT e em outros espaços públicos.

Uma vez que o projeto ainda está em andamento, o conteúdo deste trabalho deve ser entendido como um work in progress, sendo as reflexões aqui desenvolvidas de caráter preliminar e abertas a possíveis reinterpretações no futuro.

\section{Lazer e identidades LGBT}

A literatura sobre juventude tem enfatizado recorrentemente a singular relevância que os espaços de lazer possuem na vivência juvenil (ABRAMO, 1994; FRANCH, 1998). Basta percorrer qualquer um dos inúmeros roteiros noturnos das nossas cidades para perceber que existe uma presença maciça de jovens nesses lugares - ou de pessoas que, mesmo não sendo cronologicamente jovens, afinam-se com esse segmento a partir de sua imagem e atitudes. A importância dos espaços de lazer para os jovens relaciona-se com sua posição estrutural na sociedade. Como afirma Helena Abramo: 
Juventudes coloridas: sociabilidade, consumo e subjetividade entre jovens GBT em João Pessoa.

O lazer, para os jovens, aparece como um espaço especialmente importante para o desenvolvimento de relações de sociabilidade, das buscas e experiências através das quais procuram encontrar suas novas referências e identidades individuais e coletivas - é um espaço menos regulado e disciplinado do que os da escola, do trabalho e da família (ABRAMO, 1994, p. 61).

E se é na esfera do lazer que os jovens praticam, de forma mais libre e menos sujeita ao controle dos adultos, sua sociabilidade, é nela também que podem dar a conhecer aos outros suas referências identitárias, seus gostos e estilos, mediados pelo consumo de bens e serviços, postos em cena para diferenciar um grupo de outro. Nesse sentido, a esfera do lazer é mais do que um simples espaço de convívio. Pelo seu potencial de tornar visíveis práticas e atitudes distintivas, ela é também um território político, de construção e reconstrução de identidades, que podem, ou não, vir ao encontro de identidades construídas em outros espaços, notadamente na esfera política mais tradicional - partidos, sindicatos e, mais recentemente, movimentos sociais.

No caso específico do segmento LGBT, objeto deste trabalho, a esfera do lazer (embora não necessariamente ligada à condição juvenil) precede historicamente a mobilização política. Com efeito, a organização em torno da diversidade sexual tem como marco histórico o embate entre os agentes de segurança e os frequentadores de um espaço de sociabilidades homossexuais, na cidade de Nova Iorque, em 1969, na mítica Rebelião de Stonewall. Até hoje, o movimento LGBT sabe articular, como talvez nenhum outro, as dimensões do prazer, do lazer e da festa com a reivindicação política, como pode ser observado nas inúmeras paradas do orgulho LGBT pelo mundo afora, e também no Brasil. De certo modo, as mobilizações em torno da diversidade sexual, mesmo tratando temas em nada festivos, como o combate à homofobia, mantém vivo o elemento carnavalesco, atualizando continuamente a máxima de Emma Goldman: "Se não posso dançar, esta não é minha revolução". Mas embora política, lazer e, consequentemente, consumo, possam estar relacionados, realimentando-se simbolicamente, eles também podem ser territórios diversos no que diz respeito à constituição de identidades. É o que veremos a seguir, a partir da descrição contrastiva de dois "pedaços" de lazer juvenil em João Pessoa: o Empório Café e o Carboni/On the Rocks. 
Mónica Franch

\section{Conhecendo o cenário - pedaços do "Baixo Tambaú"}

Como muitas outras cidades brasileiras, João Pessoa tem um circuito ${ }^{5}$ de bares e boates que pode ser caracterizado como LGBT. Alguns esclarecimentos, contudo, precisam ser feitos antes de adentrar esse universo. Embora utilize a palavra "circuito", os espaços observados constituem pontos dispersos pelo tecido urbano, ocasionalmente comunicados pelos percursos dos mesmos sujeitos que se deslocam por entre eles, mas também podem marcar espaços descontínuos não comunicados por públicos distintos de acordo com vários critérios - orientação sexual, classe social, estilo, formas de lidar com as identidades sexuais etc.

Outra ressalva diz respeito ao uso da categoria LGBT para caracterizar o referido circuito. Embora, como assinalam Simões e Fracchini (2004), a sigla LGBT tenha sido adotada nos anos dois mil pelo movimento em convenção nacional, ela não tem uma expressão clara nos espaços noturnos juvenis. É mais comum ouvir as pessoas se referirem a bares "gays", a bares de "meninas", ou a bares "GLS", embora essa terminologia já não seja usada pelo movimento há muitos anos. Afora a diferente denominação, os espaços do circuito aqui descrito não acolhem igualmente os grupos incluídos na "sopa de letrinhas", segundo bem-humorada definição de Fracchni (2005). Alguns espaços são principalmente "L", outros são mais "G", nenhum deles é claramente "B" e apenas um deles pode ser caracterizado, de fato, como LG(B)T. Nenhum dos espaços observados é apenas " $\mathrm{T}$ ", embora exista na cidade um calendário de atividades voltado para esse grupo $^{6}$. Por fim, há espaços que, embora tenham frequência de jovens LGBT, não são identificados na cidade a partir dessa característica. Esses últimos locais são especialmente interessantes, pois nos convidam a pensar novas configurações identitárias em curso, que não passam necessariamente pela centralidade da orientação sexual.

Dois dos espaços observados nos permitirão discorrer com mais vagar sobre essas distinções e clivagens: o bar Empório Café e o Carboni. Ambos os locais

\footnotetext{
${ }^{5}$ As categorias "circuito" e "mancha" são usadas a partir de Magnani (2007).

${ }^{6}$ Incluindo os vários concursos de Miss Gay e Miss Drag, que vem sendo acompanhados desde 2009 por Silvana Nascimento.

7 Esses espaços estão sendo estudados pelos alunos Elton Bruno Amaral de Oliveira e Susi Anny Veloso. Outros espaços acompanhados pelos estudantes são: o bar Relicário, voltado ao público lésbico, e situado no bairro dos Bancários (zona norte da cidade, próximo da UFPB); a boate Vogue, que concentra, a depender do dia, todos os segmentos LGBT, e fica localizada no centro histórico; o Shopping Center Tambiá, especialmente às quartas-feiras, quando passa a ser apelidado como "Shopping Tambiba" e a Praça do Bispo, no centro da cidade. Uma pesquisadora se inseriu num grupo virtual, de acesso restrito, acompanhando seus encontros dentro e fora da rede, e um estudante está desenvolvendo sua pesquisa em lugares de trocas sexuais anônimas, nomeadamente saunas e banheiros. Em Rio Tinto, a
}

Latitude, vol. 6, n¹, pp.06-21, 2012. 
Juventudes coloridas: sociabilidade, consumo e subjetividade entre jovens GBT em João Pessoa.

situam-se na orla da cidade, mais precisamente numa "mancha de lazer" popularmente conhecida como "Feirinha de Tambaú" ou simplesmente "a Feirinha", e que concentra, no horário diurno, o comércio de artesanato voltado ao turismo e, no horário noturno, bares e restaurantes destinados à sociabilidade e ao consumo principalmente juvenis.

O primeiro desses lugares, o Empório Café, é conhecido na cidade pela sua referência ao público LGBT e pela sua inclusão no circuito de música eletrônica8 ${ }^{8}$. Trata-se de um espaço pequeno, com decoração inspirada no estilo pop-art e repertório musical com base nos ritmos eletrônicos, usualmente comandada por DJs conhecidos. Com frequência, acontecem festas de música eletrônica e outras atividades culturais, como saraus poéticos. Um dos atrativos do lugar é o cardápio, com comidas que buscam diferenciar-se do "regional" (marca presente nos diversos locais da Feirinha), servindo saladas sofisticadas, sanduíches leves e outras comidas não muito óbvias. Não se vende garrafão de cerveja e a conta, no final da noite, sai bem mais cara do que nos bares ao redor. Pode-se dizer que a proposta do ambiente é alternativa, sobretudo no terreno estético, diferenciando-se do mainstream local, marcado pela música ao vivo e os ritmos nacionais mais populares. Além de alternativa, a proposta do Empório é, de certo modo, elitista, pois se destina a uma estreita fatia de mercado, que se pode permitir pagar a diferença de preço em relação aos outros locais.

O público do Empório, em consonância, apresenta algumas características distintivas. São jovens e não tão jovens que investem monetariamente na sua imagem. Os rapazes, não raramente, ostentam roupas de grife. As jovens carregam na maquiagem e nas roupas fashion, de acordo com a terminologia local. É consenso na cena noturna pessoense que ninguém pode ir ao Empório sem um mínimo de upgrade em relação às vestimentas cotidianas. Embora não seja proibido entrar de chinelo ou em roupas informais, o desavisado que assim o faça será submetido ao escrutínio dos frequentadores. Percebe-se uma influência do estilo ligado à música eletrônica em alguns dos jovens que vão ao lugar, caracterizado pelo uso de roupas de cores vivas, que casam bem com a estética do bar. Aos finais de semana, o Empório recebe uma maior afluência de jovens. O estilo se carrega, as cores ficam mais fortes, e as fronteiras de gênero se tornam mais fluidas. Em síntese, trata-se de um lugar para ver e ser visto, com forte abertura para manifestações de homoafetividade, embora não exclusivo do público "gay" ou "lésbico".

A poucos minutos do Empório, numa área um pouco mais afastada da "muvuca" da Feirinha, outros dois bares apresentam uma proposta bem diferente.

observação ocorre na praça da cidade, às quintas-feiras no horário de tarde-noite ("quinta universitária).

${ }^{8}$ Para uma análise do circuito de música eletrônica na Paraíba, ver Dallevedo (2010). 
O Carboni e o On the Rocks 9 são locais voltados, sobretudo ao público juvenil universitário e não possuem, no imaginário da cidade, uma relação direta com o mundo LGBT. O estilo, aqui, é mais despojado. Ambos os bares possuem uma decoração bastante limpa, composta de mesas e cadeiras de madeira, com telões com exibição de vídeos de rock, estilo musical que impera nos dois locais. O rock também marca o visual dos frequentadores, que vestem, em sua maioria, roupas pretas, camisetas com nomes de bandas, calças jeans, e usam sandálias ou tênis all star. A exceção a esse predomínio das cores escuras fica por conta de alguns jovens vestindo roupas mais coloridas - e que, coincidentemente ou não, namoram pessoas do mesmo sexo. Bebidas e comidas são mais comuns, e também mais em conta do que no Empório. A proposta do lugar é, deste modo, alternativa em relação ao gosto musical, porém mais "descolada", apresentando-se a seus fregueses como um espaço "sem frescura".

Em geral, os frequentadores do Carboni não costumam ir ao Empório, e vice-versa, mas às vezes ocorre de os jovens transitarem nos dois espaços, especialmente (pelo que foi possível observar) jovens que vão ao Carboni eventualmente frequentam o Empório. Para os primeiros, o Empório é um espaço muito artificial, "caras e bocas", onde as pessoas acodem para se exibir e ostentar sua condição financeira. Como disse um dos jovens entrevistados:

Não gosto muito daqui [do Empório] porque me sinto muito observado. A galera daqui se importa demais com aparência e isso me deixa desconfortável. Enfim, acho a música muito legal e até curto em dias de semana. Mas acho um ambiente muito repressor em geral e não curto essa galera daqui. São muito boçais (OLIVEIRA, 2012).

Para esses jovens, o Carboni é um lugar onde todo mundo pode ficar mais "à vontade", pois as pessoas que o frequentam não gostam de se diferenciar economicamente umas das outras. Nesse sentido, sentem que o Carboni é um lugar onde há mais "liberdade", pois há menos policiamento entre os pares. A diferença de estilos de ambos os espaços é destacada também por esse outro jovem entrevistado: "A galera do Carboni é muito de boa, desencanada de andar muito arrumada e com roupa de marca. Não estão nem aí pra isso. O que importa mesmo é beber com os amigos".

Já para os frequentadores do Empório, o pedaço Carboni/On the Rocks é um lugar de gente pouco interessante, por dizer o mínimo. Um dos entrevistados

${ }^{9}$ A efeitos de simplificação do texto, utilizo o nome Carboni para me referir à região dos dois bares.

Latitude, vol. 6, n¹, pp.06-21, 2012. 
Juventudes coloridas: sociabilidade, consumo e subjetividade entre jovens GBT em João Pessoa.

deixou clara sua opinião sobre os frequentadores daquele espaço: "um bando de gente suja, maloqueiros e drogados". Esses jovens, em contrapartida, sentem-se bem no Empório, onde as pessoas são mais "bonitas" e o ambiente, mais festivo e alegre. A palavra "liberdade" também aparece entre os frequentadores e têm mais a ver, neste caso, com a possibilidade de encenar identidades sexuais/de gênero de maneira menos convencional. Vejamos como essa encenação ocorre nos dois espaços aqui apresentados.

\section{Ser ou não ser - encenando diferenças, contrastando identidades}

As parcerias entre pessoas do mesmo sexo podem ser observadas tanto no Empório como no Carboni, porém parecem existir diferenças no modo como elas são encenadas, e no que elas representam em termos de identidade para os frequentadores de ambos os espaços. O Empório, por se constituir no imaginário da cidade como um local dentro do circuito GLS, presta-se mais à encenação de estéticas fluídas em termos de gênero, que podem ser exemplificadas pela presença de homens com maquiagem nos olhos. E embora em ambos os espaços (como em boa parte do roteiro noturno juvenil) a paquera seja uma dinâmica importante, ela se faz mais presente no Empório, notadamente entre jovens gays. A encenação da diversidade parece ser crucial para um aspecto mais marcado pelos frequentadores do Empório Café: a relevância do lugar nas trajetórias biográficas. Para alguns jovens com os que os estudantes conversaram, frequentar o Empório faz parte do processo de "sair do armário" (VELOSO, 2012). É um dos lugares onde os jovens tornam pública sua preferência sexual/de gênero, e encontram pessoas com as quais podem partilhar sua experiência. É claro que essa não é a única identificação presente no local, pois os jovens que vão ao Empório também se diferenciam de outros em termos de poder aquisitivo e de preferências estéticas. Mas o fato de poder estar à vontade no lugar, no que diz respeito a manifestações de afeto, desejo ou interesse sexual, parece ser um aspecto relevante na escolha do Empório como local de lazer. Com efeito, carícias, beijos e outras manifestações de afeto/desejo entre pessoas do mesmo sexo encontram, no Empório, um espaço acolhedor, espaço este que transborda para as ruas nas noites de sábado, quando o fluxo de clientes se divide entre o interior e o exterior do bar, alimentando o comércio informal de bebidas e comidas.

O Carboni/On the Rocks, por sua vez, também acolhe sem reservas manifestações de interesse sexual entre pessoas do mesmo sexo. Os dois bares ocupam as ruas com mesas e cadeiras, de modo que a extensão para o espaço exterior ao bar é mais evidente do que no Empório, não se limitando aos finais de semana. Nas mesas ou por entre os carros estacionados, pessoas do mesmo sexo trocam beijos e outros afagos sem que isso se torne motivo de censura pelos convivas do bar. Contudo, não é incomum os frequentadores manifestarem 
resistência à sigla "LGBT", embora possam, eventualmente, frequentar espaços destinados ou assimilados com esse público, principalmente o Empório.

A diferença na construção das subjetividades tornou-se evidente no processo de organização do I Encontro da Juventude LGBT na Paraíba, quando os estudantes foram até os bares e outros espaços de lazer para convidar os frequentadores para o encontro. Embora os frequentadores do Empório não estivessem necessariamente interessados no evento, foi no Carboni que os estudantes encontraram maior resistência. Esse tipo de reação é um fato "bom para pensar", podendo ser revelador de mudanças nas formas de construção das subjetividades por esse segmento juvenil.

A julgar pelos relatos dos estudantes, os jovens do Carboni/On the Rocks não gostam de se definir nem de serem definidos por terceiros a partir de sua orientação sexual. São jovens que gostam de rock ou que curtem o ambiente desses dois bares. Também transitam por um circuito maior de espaços e eventos de lazer destinados/construídos por jovens "descolados", e que inclui os bares situados no centro histórico e os eventos ali realizados, alguns de nomes muito criativos como a iniciativa Vai tomar no Centro ${ }^{10}$. Esses jovens têm inúmeros gostos, inserem-se em diversas redes de sociabilidade, no mundo real e no virtual, estudam, alguns trabalham, vivem suas vidas em vários espaços sociais. Sendo assim, alguns deles consideram uma redução identitária priorizar a dimensão da orientação sexual como o elemento a partir do qual extraem sua definição social.

Essa negativa supõe uma mudança em relação ao processo histórico de construção das subjetividades no Ocidente. Se acreditarmos nas análises de Michel Foucault (1988), o dispositivo da sexualidade que foi sendo erigido no Ocidente a partir do século XVIII colocou a sexualidade como lugar da verdade, como aquilo que responde à questão crucial de quem somos nós. Quer sob a forma patologizante do saber médico, que criou o homossexual como "espécie", quer sob a bandeira identitária do movimento gay dos anos 1970, o dispositivo da sexualidade obriga a tornar pública a orientação sexual, que se torna desse modo um dado fixo na identidade social do indivíduo. O que esses jovens parecem evidenciar, contudo, é um certo esgotamento desse modelo, associado a novas formas de viver as escolhas sexuais que não necessariamente marcam as identidades dos sujeitos.

É importante salientar que a recusa a se enquadrar na sigla LGBT não decorre, como poderíamos ser levados a pensar, de uma dificuldade na vivência de

\footnotetext{
${ }^{10}$ Bloco carnavalesco fora de época que agitou o centro da cidade durante vários domingos consecutivos. Juntamente com iniciativas governamentais como o Sabadinho Bom, com apresentação de chorinho numa praça no centro comercial da cidade, o Vai tomar no Centro é revelador do esforço de certos segmentos da juventude pessoense para reapropriar-se dessas áreas por vezes degradadas da cidade e transformá-las em novos circuitos de lazer.
}

Latitude, vol. 6, n¹, pp.06-21, 2012. 
Juventudes coloridas: sociabilidade, consumo e subjetividade entre jovens GBT em João Pessoa.

uma orientação sexual não hegemônica. Contrariamente ao que ocorreu em gerações anteriores, muitos desses jovens "saem do armário" de forma bastante tranquila, encontrando acolhimento em seu círculo de amizades e até entre seus familiares. Não se trata, portanto, de jovens "enrustidos", que buscam esconder suas preferências. O que parece estar acontecendo é que esse aspecto de suas vidas não passa, necessariamente, por uma questão identitária. Deste modo o Carboni, como vários outros espaços existentes na cidade de João Pessoa, aglutina um público diverso em termos de orientação sexual, sem constituir um espaço exclusivo ou preferencial para as sociabilidades homoafetivas. Em termos de dinâmicas societais, a existência desse tipo de espaços parece atuar contra a lógica do gueto, tão importante no passado para salvaguardar a segurança e possibilitar trocas afetivo-sexuais entre pessoas do mesmo sexo. O que esses espaços sugerem é a incorporação da diversidade sexual como um dado a mais em alguns espaços de lazer em João Pessoa, portanto, a banalização das diferenças em termos de orientação sexual, ao ponto de não ser mais necessário estabelecer espaços diversos e separados entre si.

\section{Muitas cores, muitas vidas}

O Carboni e o Empório Café apresentam duas possíveis soluções ao dilema da sociabilidade em contextos marcados pela diversidade sexual. Outras experiências, em processo de mapeamento pelos jovens participantes do projeto aqui referido, mostram que são muitas as articulações possíveis nesse sentido. No bairro de Mangabeira, na zona norte da cidade, um bar de "meninas" apresenta um perfil mais afim com as identidades LGBT, divulgando a agenda do movimento na cidade e abrindo espaço para iniciativas de combate à homofobia. Outro espaço interessante para perceber tais articulações é a rede social, principalmente o Facebook, onde as encenações de gênero podem se tornar públicas ou, pelo contrário, reencontrar a dimensão do segredo.

O grupo $\mathrm{AC}^{11}$ é um exemplo dessa última escolha. Aglutinando, atualmente, 1.400 membros, com idades compreendidas entre os 15 e os 30 anos, o grupo propicia a troca de mensagens e informações na rede e faculta a possibilidade de conhecer novas pessoas, o que é facilitado pela realização de encontros presenciais na cidade de João Pessoa. Apesar desses sinais de "publicidade", o grupo é de acesso restrito, sendo necessário receber um convite para fazer parte dessa, hoje, amplíssima rede. A maneira como as sociabilidades são construídas no grupo AC revela, por um lado, a importância da orientação sexual como fator que aglutina o grupo virtual; e a necessidade de se manter tal orientação em segredo, ou no mínimo de se ter certo controle quanto a quem terá acesso a ela. Reecontramos,

${ }^{11}$ Não é possível divulgar o nome do grupo, que está sendo pesquisado pela estudante Luarna Relva Cortez. 
deste modo, uma lógica que faz parte historicamente das sociabilidades LGBT, que se constituem nas brechas das sociabilidades heteronormativas, a partir das técnicas propiciadas pelas novas tecnologias.

Quero encerrar este breve ensaio reafirmando a diversidade de cores que os jovens LGBT trazem, hoje, ao cenário das sociabilidades juvenis. Mostrando-se festivamente nas paradas e em outros eventos políticos que misturam reivindicação e festa ${ }^{12}$; agindo nas brechas possibilitadas pelos recursos tecnológicos da internet; se diferenciando ou se misturando com jovens que não necessariamente partilham as mesmas preferências sexuais, as maneiras como esses jovens resolvem estar-no-mundo são um convite para perceber mudanças e permanências na maneira como se constroem as sociabilidades desse segmento, num mundo crescentemente homofóbico e que, no entanto, nunca celebrou tanto a diversidade sexual.

\section{Referências}

ABRAMO, Helena Wendel. Cenas juvenis: punks e darks no espetáculo urbano. São Paulo: Editora Página Aberta, 1994.

D'ALLEVEDO, Pedro Tadeu Faria. O circuito-cena e.music de João Pessoa: dinâmicas locais de uma cultura jovem global. Tese (Doutorado em Sociologia). João Pessoa: Universidade Federal da Paraíba, 2011.

FRANCH, Mónica. Tardes ao léu: Um ensaio sobre os usos do tempo livre entre jovens de periferia do Recife. Dissertação (Mestrado em Antropologia). Recife: Universidade Federal de Pernambuco, 1998.

FACCHINI, Regina. Sopa de letrinhas? Movimento homossexual e produção de identidades coletivas nos anos 90. Rio de Janeiro: Garamond Seção Garamond Universitária, 2005.

FOUCAULT, Michel. A história da sexualidade I - a vontade de saber. Rio de Janeiro: Graal, 1988.

MAGNANI, José Guilherme Cantor. Circuitos de jovens. In: ; SOUZA, Bruna Mantese (orgs.). Jovens na metrópole: etnografias de circuitos de lazer, encontros e sociabilidade. São Paulo: Ed. Terceiro Nome, 2007.

OLIVEIRA, Elton Bruno. Pedaços da noite LGBT de João Pessoa: dinâmicas de lazer e lógicas de diferenciação. Relatório do projeto Diversidade Sexual e Direitos Humanos: novos olhares e ações entre movimentos sociais, agentes públicos e universidade. João Pessoa: Núcleo de Cidadania e Direitos Humanos da UFPB, 2012.

${ }^{12}$ Em João Pessoa, é significativa a adesão de segmentos da juventude LGBT à Marcha das Vadias. 
Juventudes coloridas: sociabilidade, consumo e subjetividade entre jovens GBT em João Pessoa.

SIMÕES, Júlio; FACCHINI, Regina. Na trilha do arco-íris. Do movimento homossexual ao LGBT. São Paulo: Editora Fundação Perseu Abramo, 2009.

VELOSO, Susi Anny. Afirmações da diferença na construção identitária de grupos LGBT'S na Paraíba. Relatório do projeto Diversidade Sexual e Direitos Humanos: novos olhares e ações entre movimentos sociais, agentes públicos e universidade. João Pessoa: Núcleo de Cidadania e Direitos Humanos da UFPB, 2012. 